\title{
Pregabalin in the treatment of inferior alveolar nerve paraesthesia following overfilling of endodontic sealer
}

\author{
Oscar Alonso-Ezpeleta ${ }^{1}$, Pablo-J. Martín ${ }^{2}$, José López-López ${ }^{3}$, Lizett Castellanos-Cosano ${ }^{2}$, Jenifer Martín- \\ González $^{2}$, Juan-J. Segura-Egea ${ }^{4}$

\footnotetext{
${ }^{1}$ Associate Professor. Department of Endodontics, School of Dentistry, University of Zaragoza, 22006-Huesca, Spain

${ }^{2}$ Doctoral fellow. Department of Stomatology, School of Dentistry, University of Sevilla, C/ Avicena s/n, 41009-Sevilla, Spain

${ }^{3}$ Professor. Department of Odontostomatology, University of Barcelona, Barcelona, Spain

${ }^{4}$ Full Professor. Department of Endodontics, School of Dentistry, University of Sevilla, C/ Avicena s/n, 41009-Sevilla, Spain
}

\author{
Correspondence: \\ Department of Stomatology (Endodontics) \\ School of Dentistry, University of Sevilla \\ C/ Avicena S/N, 41009, Sevilla, Spain \\ segurajj@us.es
}

Received: $12 / 12 / 2013$

Accepted: 23/12/2013

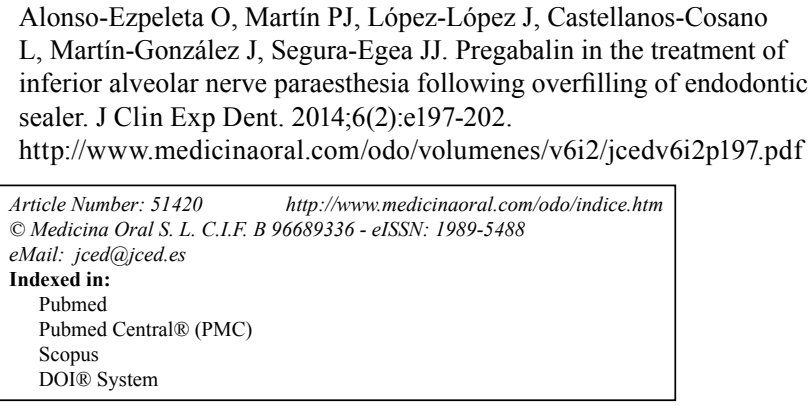

\begin{abstract}
A case of orofacial pain and inferior alveolar nerve (IAN) paraesthesia after extrusion of endodontic sealer within the mandibular canal treated with prednisone and pregabalin is described. A 36-year-old woman underwent root canal treatment of the mandibular second right premolar tooth. Post-operative panoramic radiograph revealed the presence of radiopaque canal sealer in the mandibular canal. Damage to IAN consecutive to extrusion of endodontic sealer was diagnosed. Non-surgical management was decided, including: $1 \mathrm{mg} / \mathrm{kg} / \mathrm{day}$ prednisone 2 times/day, once-daily regimen, and $150 \mathrm{mg}$ /day pregabalin, two doses per day, monitoring the progress with periodic follow-up visits. Six weeks after the incident the signs and symptoms were gone. The complete resolution of paraesthesia and the control of pain achieved suggest that a non-surgical approach, combining prednisone and the GABA analogue pregabalin, is a good option in the management of the IAN damage subsequent to endodontic sealer extrusion.
\end{abstract}

Key words: Endodontics, inferior alveolar nerve, neuropathic pain, orofacial pain, paraesthesia, pregabalin.

\section{Introduction}

Injuries of the inferior alveolar nerve (IAN), represent a rare but serious complication of dental treatment (1). Overinstrumentation during root canal treatment with manual or rotary instruments can perforate the mandibular canal. This allows the extrusion of endodontic sealers, dressing agents, and irrigation solutions out of the tooth and into the canal that may lead to IAN injury (2). Although small material extrusions are generally well tolerated by the periradicular tissues (3), clinical symptoms are disabling sensory disturbances such as pain, dysesthesia, paresthesia, hypoesthesia, and anesthesia, which have been reported after the extrusion of endodontic materials into the mandibular canal. Almost all of the endodontic materials are neurotoxic at some level and are able to initiate a inflammatory process which causes damage to cells and might culminate in necrosis of the tissue $(3,4,5,6,7,8,9)$. 
Paresthesia might be caused by several factors, both local and systemic. Local factors are, for example, the use of local anesthetics, trauma, local infections, neoplasia, tooth extraction, and endodontic related complications. Systemic factors are, for example, microbial infections, multiple sclerosis, lymphoma, or diabetes mellitus (4, $10)$.

The normal therapeutic sequence for injuries to IAN is the control of pain and inflammation and, whenever possible, the surgical elimination of the cause (11). However, total resolution of pain and reduction or disappearance of paraesthesia after a non-surgical management have been reported $(3,7,8,9,12)$.

Pregabalin is a GABA analogue with similar structure and actions to gabapentin. It has antiepileptic, analgesic and anxiolytic activity. Its ability to reduce neurotransmitter release from activated neurons in pain pathways and fear circuits may contribute to its role as an adjuvant in pain management and as anxiolytics. Pregabalin has proven effect in chronic and neuropathic pain (13-15).

The aim of this paper is to describe a case of endodontic sealer penetration within the mandibular canal after root canal treatment of a mandibular right second premolar, with resolution of pain and paraesthesia after a non-surgical approach, including treatment with prednisone and pregabalin.

\section{Case Report}

A 36-year-old woman requested dental attention to her dentist. The main complaints were pain and swelling in the right mandibular second premolar (\#45). Panoramic radiograph revealed widening of periodontal ligament space in the root apex of the affected tooth (Fig. 1). Acute apical periodontitis subsequent to caries was diagnosed and root canal treatment was carried out. One day after endodontic treatment, the patient had severe pain in the treated tooth and numbness on the right side of the lower lip that extended from the mandibular midline to the second premolar. Her dentist prescribed ibuprofen during one week, but after that time, pain and paresthesia persisted, without any kind of improvement. The extraction of the right mandibular second premolar tooth was decided. Two weeks after extraction, pain had not completely disappeared, and paresthesia remained. Panoramic radiograph showed radiopaque material within the mandibular canal (Fig. 2). The dentist diagnosed

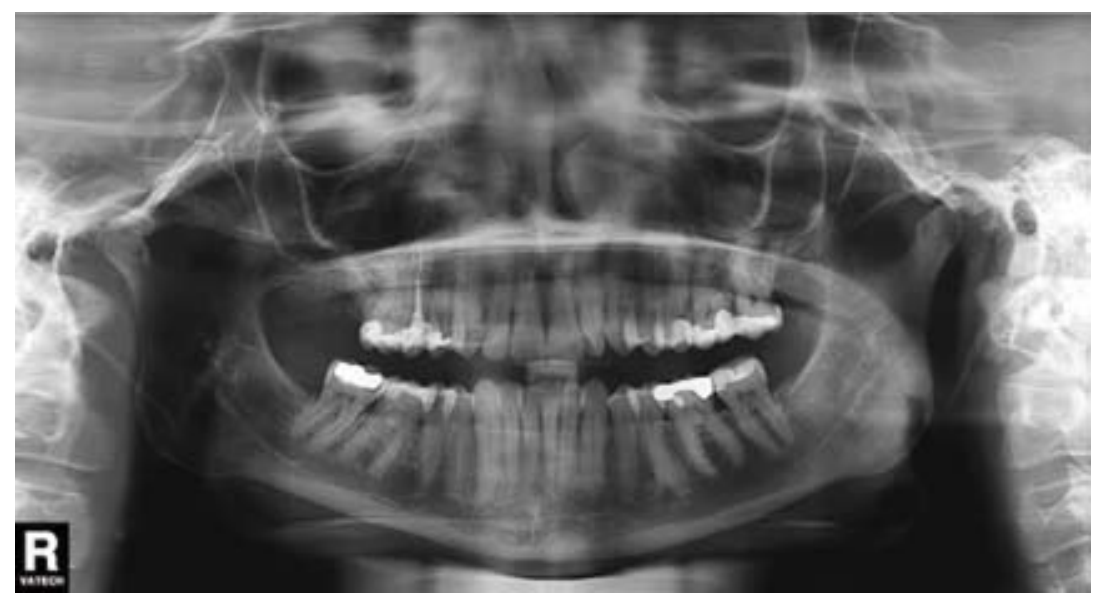

Fig. 1. Panoramic radiograph revealed widening of periodontal ligament space in the root apex of the right mandibular second premolar.

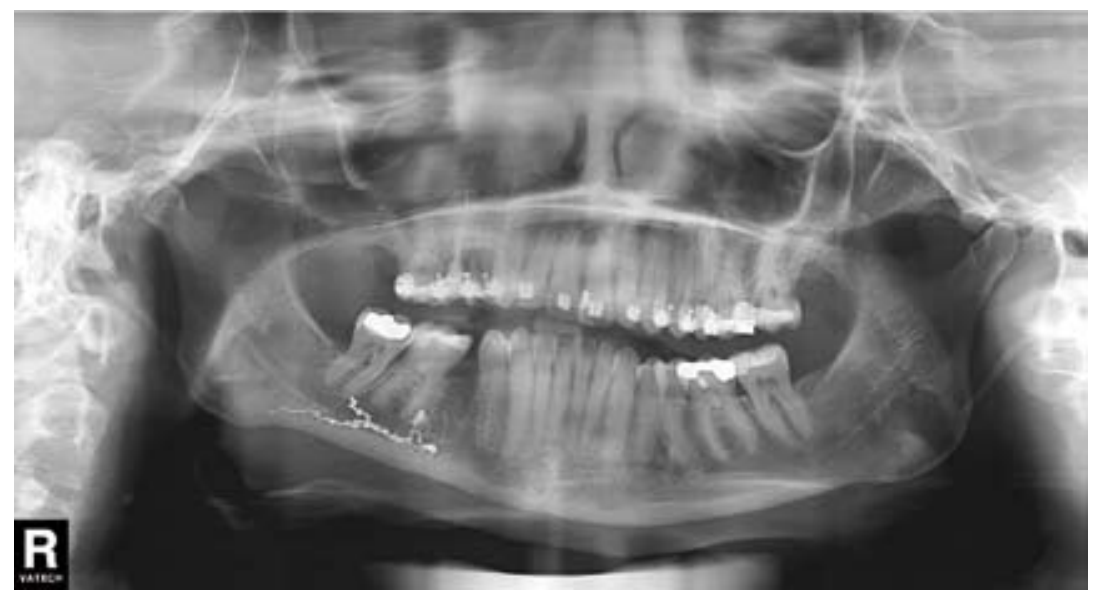

Fig. 2. Panoramic radiograph revealing the presence of radiopaque material (endodontic sealer) within the mandibular canal. Tooth 45 has been extracted. 
neuropathic pain and inferior alveolar nerve paresthesia after extrusion of endodontic sealer and then, decided to refer the patient to the University Dental Clinic.

The referring dentist communicated that the root canal treatment was done with adequate anaesthesia and isolation with rubber dam. The endodontic access cavity was prepared with round diamond burs, Komet 014 (Gebr. Brasseler $\mathrm{GmbH}$, Lemgo, Germany). One canal orifice was found. Apical patency was carried out, and working length was determined electronically using Dentaport ZX (J. Morita Mfg. Corp. Higashihama Minami-cho, Fushimi-ku, Kyoto, Japan). The root canal was irrigated with $0,2 \%$ chlorhexidine (CHX) and instrumented with Reciproc R25 (VDW GmbH, Munich, Germany). After cleaning and shaping, the canal was dried and filled with AH Plus Jet (Dentsply DeTrey GmbH, Konstanz, Germany) and gutta-percha, using the lateral compaction technique. A small quantity of sealer was introduced into the root canal using an intra-oral adjustable tip attached with this sealer. Then the main gutta-percha cone was placed, coated with a minimal quantity of sealer. Cold compaction was had performed with a digital spreader and auxiliary gutta-percha cone which was covered with a small quantity of sealer.

The anaesthetized zone in the region innervated by the right inferior alveolar nerve was delimited by tactile exploration with an explorer (Fig. 3). Neither buccal gingival tissues nor the lower lip between the midline and the second premolar showed sensitivity to thermal or mechanical stimuli.

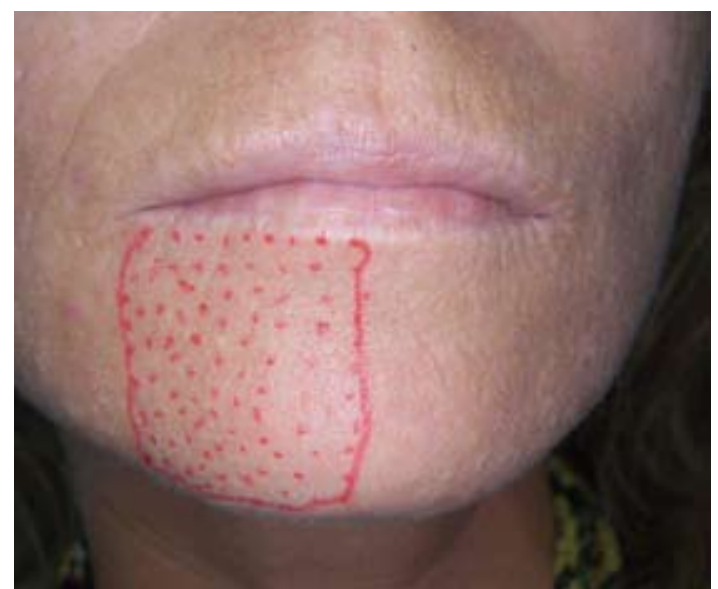

Fig. 3. Three weeks after the accident during the root canal treatment, a delimitation of the mental nerve anaesthesia is performed.

After discussing treatment options with the patient, who refused surgical debridement of the mandibular canal and decompression of the inferior alveolar nerve, a non-surgical approach was therefore decided. Treatment started with anti-inflammatory regimen including $1 \mathrm{mg} / \mathrm{kg} /$ day of prednisone (Dacortin ${ }^{\circledR}, 30 \mathrm{mg}$; Merck SL, Madrid, Spain) in two doses, in a gradually reducing regimen on a daily basis, and $150 \mathrm{mg}$ per day of pregabalin (Lyrica ${ }^{\circledR}, 75 \mathrm{mg}$; Pfizer SL, Barcelona, Spain), two doses by day, monitoring the progress with periodic follow-up visits.

The patient noticed a significant improvement in the first days after the medical treatment. One week later, the patient had no pain, and paraesthesia in the region of the right lower lip had decreased more than half of its surface. The prednisone was stopped but the pregabalin regimen was maintained. Three weeks later, the paraesthesia was reduced substantially compared with the initial situation (Fig. 4) and pregabalin treatment was finished. Panoramic radiograph was taken, revealing a significant reduction in the amount of endodontic sealer within the mandibular canal (Fig. 5, Fig. 6). The patient reported a gradual reduction of paraesthesia and after six weeks signs and symptoms had disappeared.

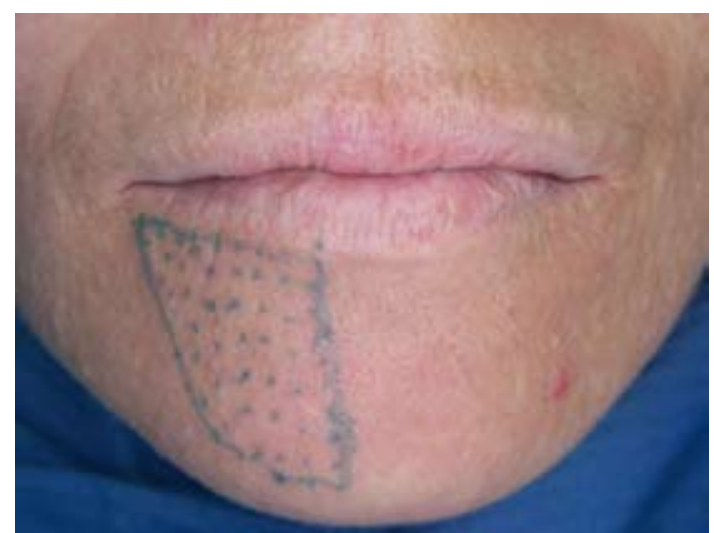

Fig. 4. Three weeks after treatment with pregabalin and prednisone the area of mental nerve anaesthesia has decreased substantially.

\section{Discussion}

A case of neuropathic pain and inferior alveolar nerve paresthesia after extrusion of endodontic sealer within the mandibular canal has been described. Most of published cases of paresthesia related to endodontics might be caused by overinstrumentation and/or overfill of endodontic materials into the mandibular canal $(1,10)$. IAN injuries have been reported in relation with endodontic treatment in second mandibular molars, because the distance between the apexes and the mandibular canal is often less than $1 \mathrm{~mm}$. However, first molars and premolars must be also taken into consideration $(11,16,17)$.

Overinstrumentation and/or overfilling of mandibular molar and premolar are a potential iatrogenic cause of IAN injury (18). Gutta-percha is traditionally considered an inert root-filling material, and the paresthesia cases involving gutta-percha usually result from overfill of thermoplastic gutta-percha. If the sealer is extruded in the mandibular canal space, it can cause problems that vary from mild inflammatory reactions to severe neurotoxic damage $(11,19,20)$. 


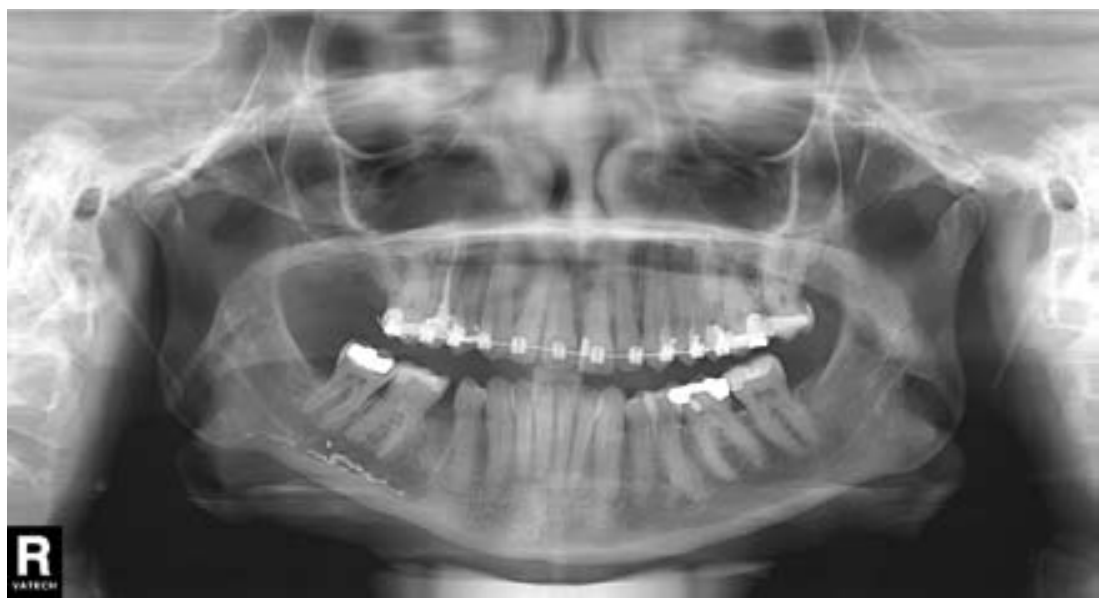

Fig. 5. Panoramic radiograph after three weeks of treatment with pregabalin and prednisone.

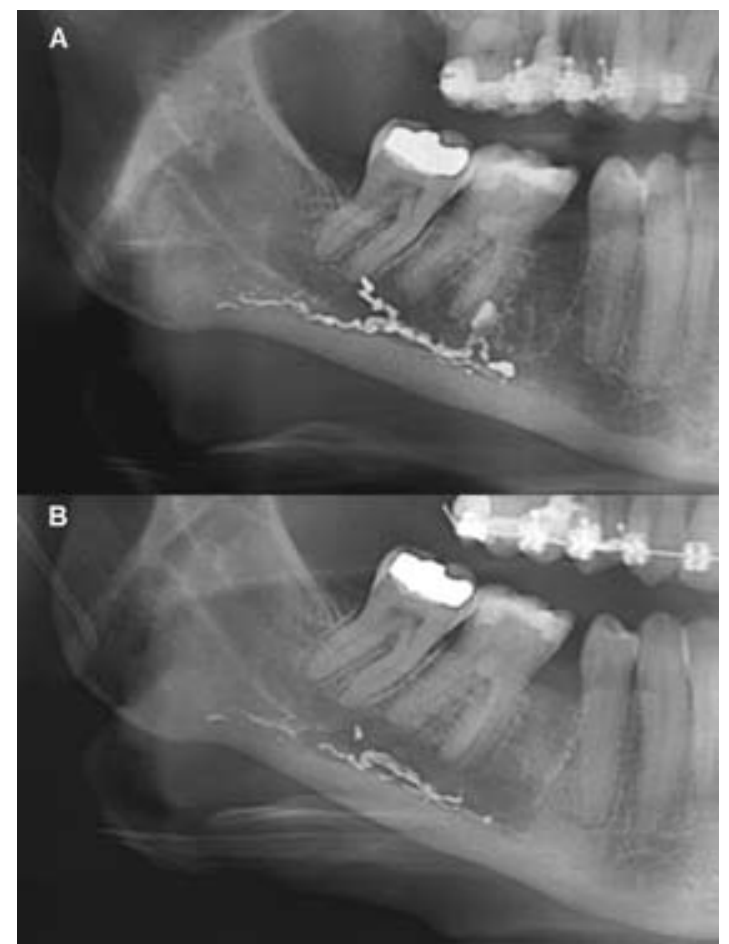

Fig. 6. A) Initial panoramic radiograph detail. B) Panoramic radiograph detail after three weeks of treatment. A significant reduction in the amount of endodontic sealer within the mandibular canal is observed.

Severe endodontic pain after endodontic sealer extrusion requires early diagnosis and prompt management to reduce the risk of permanent nerve damage. Conebeam computed tomography (CBCT) is often useful in monitoring the area of tissue damage in relation to hard tissues (eg. the location of extruded material in relation to mandibular canal or mental foramen) $(21,22)$.

The literature describes four possibilities of endodontic sealer spreading to the periapical region: toward the mandibular canal, drainage through lymphatic vessels, systemic diffusion through a periapical vein and progression toward soft tissues between bone and mucosal membrane $(3,23)$. The case reported here corresponds with the first of these routes.

The first symptom of overextension into the mandibular canal is sudden pain during filling of the root canal, which persists after the disappearance of the local anaesthetic (24). The literature provides ample evidence that this might induce mild or serious transient inflammatory responses $(25,26)$. Due to this, pain can be accompanied by local inflammatory signs with painful tooth to percussion, painful upon palpation of the buccal alveolar process or a combination of signs of mechanical trauma and inferior dental nerve inflammation with pain or numbness of the lower lip or otalgia (27). Some patients experience persistent anaesthesia $(1,10,28,29)$. In the present case, symptoms occurred after one day, and pain was associated with paraesthesia.

Damage by accidental extrusion of sealer into the mandibular canal may occur due to mechanical, thermal, or chemical processes $(4,6,9,30)$. In the case described here, AH Plus Jet extruded into the mandibular canal. This sealer is commercialized as a syringe of automix, with a final cannula that introduces it into the canal. This sealer is commercially as a syringe of automix, with a final cannula that introduces it into the canal. It is an open-end cannula, therefore it could be applied the same as the irrigation needles. Lots of bibliographic sources conclude that these have higher probability of apical extrusion $(31,32,33)$. Because of the use of this mechanism in the inclusion of cement on the root canal, it was able to facilitate its extrusion by the apex.

AH Plus Jet is a commonly used epoxy resin-based root canal sealer with the monomer 2,2-bis(4-(2-hydroxy-3 -methacrylyloxypropoxy) phenyl)-propane (BisGMA), prepared from bisphenol A and glycidyl methacrylate, as its major ingredient (34). Previous reports have shown that AH Plus can cause cytotoxic effects (35) and neu- 
rotoxicity when extruded into the mandibular canal (8). Moreover, it has been shown that its component bisphenol A can also cause cytotoxicity (36). The cytotoxic effect of AH Plus has been shown to be dependent on the setting time, showing a significant reduction after 7 days (37). In a recent study of the cytotoxicity of AH Plus, there was no evidence for DNA double-strand breaks caused; so far, there are no reports in the literature on the occurrence of periapical malignant lesions that might be caused by the extrusion of root canal sealer (38).

In this case, polymerization of the sealer may explain, at least in part, the rapid improvement observed in the first days after the incident. Gutta-percha and sealers may cause both an inflammatory reaction and pain when extruded beyond the root canal system. The nature and degree of tissue reaction is related to the type and amount of sealer, the location of the extrusion, and the condition of periodontal tissues (30). Even root canal sealants that are believed to be more benign, such as zinc oxide, eugenol, and calcium hydroxide (owing to high $\mathrm{pH}$ ), have been shown to be neurotoxic in vitro and are more certainly neurotoxic in vivo (40). In some experimental studies it was shown that paraformaldehyde is a polymeric hydrate of formaldehyde, which when in contact with water releases formaldehyde gas, and may cause permanent damage to the nerve (41).

Treatment of this endodontic complication remains controversial, varying from a wait-and-see approach, including anti-inflammatory drugs and periodic followup $(3,7,8,9,12)$, to early, if not immediate, surgical debridement of the inferior alveolar nerve involving bone removal of the vestibular cortical plate $(2,6,18)$ or sagittal mandibulotomy (19). The patient refused surgical debridement of the inferior alveolar canal and decompression of the inferior alveolar nerve, and decided to make the extraction of second lower right premolar. So, a non-surgical management was agreed including antiinflammatory treatment with prednisone and analgesic treatment with pregabalin.

Most of the pain treatments used for neuropathic pain have not been approved by FDA, including all the tricyclic antidepressants and most of the anticonvulsants. Two medications are approved for peripheral neuropathy by the FDA; duloxetine and pregabalin (42). In July 2004 pregabalin was granted approval in all European member states for the treatment of peripheral neuropathic pain. Pregabalin is an analogue of the inhibitory neurotransmitter gamma-aminobutyric acid (GABA). Although its main indication is chronic pain and trigeminal neuropathic pain $(14,43)$, it has been frequently used in neuropathic pain (44). Pregabalin has shown analgesic activity in preclinical and clinical models, observing a significant improvement as early as week 1 and is maintained throughout the period of treatment $(45,46)$ and appears to have significant analgesic properties fol- lowing third molar extraction (47). Peak plasma levels occur approximately 1 hour after oral doses and oral bioavailability is approximately $90 \%$. Pregabalin is not protein-bound and exhibits a plasma half-life of 6 hours, which is not dose-dependent. These antiepileptic drugs have a favorable safety profile with minimal concerns regarding drug interactions and showing no interference with hepatic enzymes (48). Hepatic metabolism is negligible, and most of the oral dose (95\%) is eliminated by renal excretion. Pregabalin is a safe and well-tolerated new treatment for neuropathic pain and the most common side effects included dizziness, and somnolence, peripheral edema, weight gain, and asthenia, but this finding was not reported in this case $(13,49)$. Taking into account that endodontic sealer extrusion into the mandibular canal damages the inferior alveolar nerve triggering neuropatic pain, the use of pregabalin in the case reported here was justified.

The complete resolution of the paraesthesia and the control of pain achieved in the present case, suggests that a non-surgical approach combining prednisone and pregabalin is a good option in the management of inferior alveolar nerve damage subsequent to endodontic sealer extrusion. If medical treatments have failed, invasive therapies such as intrathecal drug administration and neurosurgical techniques may be considered.

\section{References}

1. Givol N, Rosen E, Bjorndal L, Taschieri S, Ofec R, Tsesis I. Medico-legal aspects of altered sensation following endodontic treatment: a retrospective case series. Oral Surg Oral Med Oral Pathol Oral Radiol Endod. 2011;112:126-31.

2. Koseoglu BG, Tanrikulu S, Sübay RK, Sencer S. Anesthesia following overfilling of a root canal sealer into the mandibular canal: A case report. Oral Surg Oral Med Oral Pathol Oral Radiol Endod. 2006;101:803-6.

3. Poveda R, Bagán JV, Diaz Fernández JM, Sanchis JM. Mental nerve paresthesia associated with endodontic paste within the mandibular canal: report of a case. Oral Surg Oral Med Oral Pathol Oral Radiol Endod. 2006;102:e46-e9.

4. Morse DR. Infection-related mental and inferior alveolar nerve paresthesia: Literature review and presentation of two cases. J Endod. 1997;23:457-60.

5. Ahlgren FKEK, Johannessen AC, Hellem S. Displaced calcium hydroxide paste causing inferior alveolar nerve paraesthesia: report of a case. Oral Surg Oral Med Oral Pathol Oral Radiol Endod. 2003;96:734-7.

6. Gallas-Torreira MM, Reboiras-López MD, García-García A, Gándara-Rey J. Mandibular nerve paresthesia caused by endodontic treatment. Med Oral Patol Oral Cir Bucal. 2003;8:299-303.

7. Froes FG, Miranda AM, Abad Eda C, Riche FN, Pires FR. Nonsurgical management of paraesthesia and pain associated with endodontic sealer extrusion into the mandibular canal. Aust Endod J. 2009;35:183-6.

8. González-Martín M, Torres-Lagares D, Gutiérrez-Pérez JL, SeguraEgea JJ. Inferior alveolar nerve paresthesia after overfilling of endodontic sealer into the mandibular canal. J Endod. 2010;36:1419-21.

9. López-López J, Estrugo-Devesa A, Jané-Salas E, Segura-Egea JJ. Inferior alveolar nerve injury resulting from overextension of an endodontic sealer: non-surgical management using the GABA analogue pregabalin. Int Endod J. 2012;45:98-104.

10. Ahonen M, Tjäderhane L. Endodontic-related paresthesia: A case 
report and literature review. J Endod. 2011;37:1460-4.

11. Pogrel MA. Damage to the inferior alveolar nerve as the result of root canal therapy. J Am Dent Assoc. 2007;138: 65-9.

12. Blanas N, Kienle F, Sándor GKB. Inferior alveolar nerve injury caused by thermoplastic gutta-percha overextension. J Can Dent Assoc. $2004 ; 70: 384-7$

13. Zareba G. Pregabalin: a new agent for the treatment of neuropathic pain. Drugs Today (Barc.). 2005;41:509-16.

14. Ferré-Corominas J, Chimenos-Kustner E, López-López J. Odontologic considerations in fibromyalgia. Med Clín. (Barc.). 2011;137:27-9.

15. Jain P, Jolly A, Bholla V, Adatia S, Sood J. Evaluation of efficacy of oral pregabalin in reducing postoperative pain in patients undergoing total knee arthroplasty. Indian J Orthop. 2012;46:646-52.

16. Tilotta-Yasukawa F, Millot S, El Haddioui A, Bravetti P, Gaudy JF. Labiomandibular paresthesia caused by endodontic treatment: an anatomic and clinical study. Oral Surg Oral Med Oral Pathol Oral Radiol Endod. 2006;102:47-59.

17. Ngeow WC. Is there a "safety zone" in the mandibular premolar region where damage to the mental nerve can be avoided if periapical extrusion occurs? J Can Dent Assoc. 2010;76:a61.

18. Escoda-Francoli J, Canalda-Sahli C, Soler A, Figueiredo R, GayEscoda C. Inferior alveolar nerve damage because of overextended endodontic material: a problem of sealer cement biocompatibility? J Endod. 2007;33:1484-9.

19. Scolozzi P, Lombardi T, Jaques B. Successful inferior alveolar nerve decompression for dysesthesia following endodontic treatment report of four cases treated with mandibular sagittal osteotomy. Oral Surg Oral Med Oral Pathol Oral Radiol Endod. 2004;97:625-31.

20. Yamaguchi K, Matsunaga T, Hayashi Y. Gross extrusion of endodontic obturation materials into the maxillary sinus: a case report. Oral Surg Oral Med Oral Pathol Oral Radiol Endod. 2007;104:131-4.

21. Giuliani M, Lajolo C, Deli G, Silveri C. Inferior alveolar nerve paresthesia caused by endodontic pathosis: a case report and review of the literature. Oral Surg Oral Med Oral Pathol Oral Radiol Endod. 2001;92:670-4.

22. Gambarini G, Plotino G, Grande NM, Testarelli L, Prencipe M, Messineo D, Fratini L, D'Ambrosio F. Differential diagnosis of endodontic-related inferior alveolar nerve paraesthesia with cone beam computed tomography: a case report. Int Endod J. 2011;44:176-81.

23. Alantar A, Tarragano H, Lefèvre B. Extrusion of endodontic filling material into the insertions of the mylohyoid muscle. Oral Surg Oral Med Oral Pathol. 1991;78:646-9.

24. LaBanc JP, Epker BN. Serious inferior alveolar nerve dyesthesia alter endodontic procedure: report of three cases. J Am Dent Assoc. 1984;108:605-7.

25. Scarparo RK, Grecca FS, Fachin EV. Analysis of tissue reactions to methacrylate resin-based, epoxy resin-based, and zinc oxide-eugenol endodontic sealers. J Endod. 2009;35:229-32.

26. Zmener O, Banegas G, Pameijer $\mathrm{CH}$. Bone tissue response to a methacrylatebased endodontic sealer: a histological and histometric study. J Endod. 2005;31:457-9.

27. Tamse A, Kaffe I, Littner MM. Paraesthesia following over extension of AH26: report of two cases and review of the literature. J Endod. 1982;8:88-90.

28. Rowe AHR. Damage to the inferior dental nerve during or following endodontic treatment. Br Dent J. 1983;153:306-7.

29. Grotz KA, Al-Nawas B, de Aguiar EG, Schulz A, Wagner W. Treatment of injuries to the inferior alveolar nerve after endodontic procedures. Clin Oral Inv. 1998;2:73-6.

30. Fanibunda K, Whitworth J, Steele J. The management of thermomechanically compacted gutta percha extrusion in the inferior dental canal. Br Dent J. 1998;184:330-2.

31. Boutsioukis C, Verhaagen B, Versluis M, Kastrinakis E, Wesselink PR, Van der Sluis LW. Evaluation ofirrigant flow in the root canal using different needle types by an unsteady computational fluid dynamics model. J Endod. 2010;36:875-9.

32. Altundasar E, Nagas E, Uyanik O, Serper A. Debris and irrigant extrusion potential of 2 rotary systems and irrigation needles. Oral
Surg Oral Med Oral Pathol Oral Radiol Endod. 2011;112:31-5. 33. Boutsioukis C, Lambrianidis T, Verhaagen B, Versluis M, Kastrinakis E, Wesselink PR, van der Sluis LW. The effect of needle-insertion depth on the irrigant flow in the root canal: evaluation using an unsteady computational fluid dynamics model. J Endod. 2010;36:1664-8.

34. Peutzfeldt A. Resin composites in dentistry: the monomer systems. Eur J Oral Sci. 1997;105:97-116.

35. Pulgar R, Segura-Egea JJ, Fernández MF, Serna A, Olea N. The effect of AH 26 and AH Plus on MCF-7 breast cancer cells proliferation in vitro. Int Endod J. 2002;35:551-6.

36. Segura-Egea JJ, Jiménez-Rubio A, Pulgar R, Olea N, Guerrero JM, Calvo JR. In vitro effect of the resin component bisphenol A on macrophage adhesion to plastic surfaces. J Endod. 1999;25:341-4.

37. Miletic I, Jukic S, Anic I, Zeljezic D, Garaj-Vrhovac V, Osmak M. Examination of cytotoxicity and mutagenicity of $\mathrm{AH} 26$ and AH Plus sealers. Int Endod J. 2003;36:330-5.

38. Van Landuyt KL, Geebelen B, Shehata M, Furche SL, Durner J, Van Meerbeek B, Hickel R, Reichl FX. No evidence for DNA doublestrand breaks caused by endodontic sealers. J Endod. 2012;38:63641.

39. Ektefaie MR, David HT, Poh CF. Surgical resolution of chronic tissue irritation caused by extruded endodontic filling material. J Can Dent Assoc. 2005;71:487-90.

40. Schmalz G, Hørsted-Bindslev P. Root canal filling materials. In: Bergenholtz G, Hørsted-Bindslev P, Reit C, editors. Textbook of endodontology. Oxford: Wiley-Blackwell; 2010. p. 193-218.

41. Brkic A, Gürkan-Köseoglu B, Olgac V. Surgical approach to iatrogenic complications of endodontic therapy: A report of 2 cases. Oral Surg Oral Med Oral Pathol Oral Radiol Endod. 2011;107:50-3.

42. Barrett AP, Smith MW. Maxillary nerve involvement in bacterial endocarditis. Int J Oral Maxillofac Surg. 1985;43:816-7.

43. Zakrzewska JM. Medical management of trigeminal neuropathic pains. Expert Opin Pharmacother. 2010;11:1239-54.

44. Blommel ML, Blommel AL. Pregabalin: an antiepileptic agent useful for neuropathic pain. Am J Health Syst Pharm. 2007;64:1475-82. 45. Bender G, Gosset J, Florian J, Tan K, Field M, Marshall S, DeJongh J, Bies R, Danhof M. Population pharmacokinetic model of the pregabalin-sildenafil interaction in rats: application of simulation to preclinical PK-PD study design. Pharmac Res. 2009;26:2259-69.

46. Buvanendran A, Kroin JS, Kari MR, Tuman KJ. A new knee surgery model in rats to evaluate functional measures of postoperative pain. Anesth Analg. 2008;107:300-8.

47. Hill CM, Balkenohl M, Thomas DW, Walker R, Mathé H, Murray G. Pregabalin in patients with postoperative dental pain. Eur J Pain. 2001;5:119-24

48. Cohen DM, Reinhardt RA. Systemic sclerosis presenting with Horner's syndrome and mandibular paresthesia. Oral Surg Oral Med Oral Pathol. 1982;53:577-81.

49. Birkan TO, Salih C, Ercan D. Paresthesia of the mental nerve stem from periapical infection of mandibular canine tooth: a case report, Oral Surg Oral Med Oral Pathol Oral Radiol Endod. 2008;105:e2831.

\section{Conflict of interest}

The authors declare that they have no conflict of interest. 